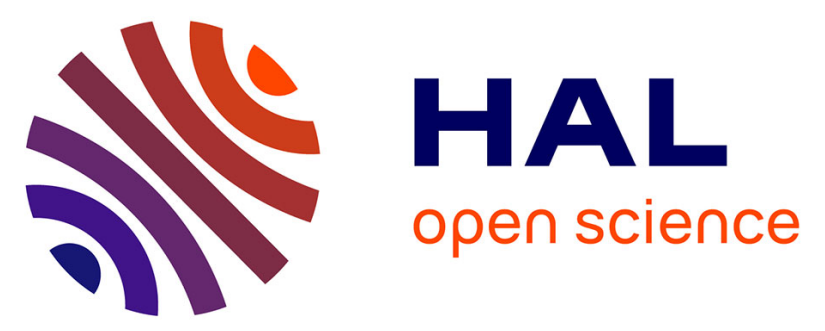

\title{
Properties of A Supercritical Quasi-Perpendicular Interplanetary Shock Propagating in Super-Alfvénic Solar Wind: from MHD to Kinetic Scales
}

Mingzhe Liu, Zhongwei Yang, D. Liu Ying, Bertrand Lembège, Karine Issautier, Lynn Bruce Wilson Iii, Siqi Zhao, Vamsee Krishna Jagarlamudi, Xiaowei Zhao

\section{To cite this version:}

Mingzhe Liu, Zhongwei Yang, D. Liu Ying, Bertrand Lembège, Karine Issautier, et al.. Properties of A Supercritical Quasi-Perpendicular Interplanetary Shock Propagating in Super-Alfvénic Solar Wind: from MHD to Kinetic Scales. 23rd EGU General Assembly, Apr 2021, Online, Unknown Region. 10.5194/egusphere-egu21-4908 . hal-03451671

\author{
HAL Id: hal-03451671 \\ https://hal.science/hal-03451671
}

Submitted on 2 Mar 2022

HAL is a multi-disciplinary open access archive for the deposit and dissemination of scientific research documents, whether they are published or not. The documents may come from teaching and research institutions in France or abroad, or from public or private research centers.
L'archive ouverte pluridisciplinaire HAL, est destinée au dépôt et à la diffusion de documents scientifiques de niveau recherche, publiés ou non, émanant des établissements d'enseignement et de recherche français ou étrangers, des laboratoires publics ou privés. 
Properties of A Supercritical Quasi-Perpendicular Interplanetary Shock Propagating in Super-Alfvénic Solar Wind: from MHD to Kinetic Scales Mingzhe Liu ${ }^{1,2,3}$, Zhongwei Yang ${ }^{2}$, Ying D. Liu ${ }^{2,4}$, Bertrand Lembège ${ }^{3}$, Karine Issautier ${ }^{1}$, L. B. Wilson III', Siqi Zhao ${ }^{6}$, Vamsee Krishna Jagarlamudi' ${ }^{7}$, Xiaowei Zhao

\section{EGU21-4908}

LESIA

Mi

We investigate the properties of an interplanetary shock $\left(\mathrm{M}_{\mathrm{A}}=3,0, \theta_{\mathrm{B}}=80^{\circ}\right)$ propagating in SupeWe investigate the properties of an interplaner $12^{\text {th }} 1999$ with in situ Wind/MFI and Wind/3DPP
Alfvénic solar wind observed on September observations. Key results are obtained concerning the possible energy dissipation mechanisp across the shock and how the shock modifies the ambient solar wind at MHD and kinetic scales: (1) Waves observed in the far upstream of the shock are incompressional and mostly shear Alfvén waves. (2) In the downstream, the shocked solar wind shows both Alfvénic and mirror-mode features due to the coupling between the Alfvén waves and ion mirror-mode waves. (3) Specularly eflected gyrating ions, whistler waves, and ion cyclotron waves are observed around the shock amp, indicating that the shock may rely on both particle reflection and wave-particle interactions for energy dissipation. (4) Both ion cyclotron and mirror mode instabilities may be excited in the downstream of the shock, since the proton temperature anisotropy touches their thresholds due to he enhanced proton temperctire ans shock number and energy flux together with the normal betatron acceleration of electrons across the
shock. (6) The shock may be somehow connected to the electron foreshock region of the Earth's bow shock, since $\mathrm{B}_{>}>0, \mathrm{~B}<0$, and the electron flux varies only when the electron pitch angles are less than $\mathrm{PA}=90^{\circ}$, which should be further investigated.

2. Research background and motivations

2.1 Research background
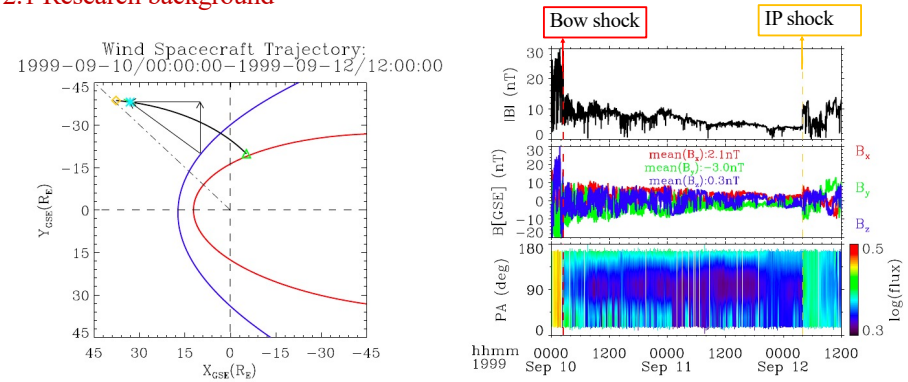

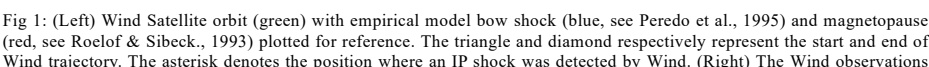
Wind trajectory. The asterisk denotes the position where an II shock was detected by Wind. (Right) The Wind observations
which corresponds to the trajectory shown in the left. From top to bottom, the panels show the magnetic field magnitude, GSE components of the magnetic field, pitch-angle distribution of $340 \mathrm{eV}$ electrons. (1) $\mathrm{M}_{\mathrm{F}}=2.1$ \& $\mathrm{MA}_{\mathrm{A}}=3.0$ : Supercritical; $\theta \mathrm{Bn}=80$ deg: Quasi-perpendicular;

The IP shock was immersed in the quasi-parallel region of the Earth's bow shock. (1) Time: 03:57:56 UT on September 12th, 1999

(2) Location: GSE (33.1, - -38.1, -3.9) RE; To the Earth's bow shock: $\sim 34.0 \mathrm{RE}$

$>$ When IP shocks are Earth-directed, how IP shock interact with the foreshock region of Earth's bow shock? Mutual affectation on each other.

- Alfvén waves/fluctuations are usually observed in the foreshock region of Earth's bow shock (eg., Wang et al., 2015 and references therein): Properties of IP shock propagating in the high-

D The properties of the bow-shock-reflected electrons and how they are affected by the IP shock. bservatoire de Paris, Université PSL, CNRS, 92195, Meudon, France; mingzhe.liu@obspm.fr;

2. State Key Laboratory of Space Weather, NSSC, CAS, Beijing 100190, China 4. University of Chinese Academy of Sciences, Beijing 100049, China

5. NASA Goddard Space Flight Center, Code 672, Greenbelt, Maryland, MD20707, USA

Deutsches Elektronen Synchrotron (DESY), Platanenallee 6, D-15738 Zeuthen, Germany Institute for Astrophysics- Institute for Space Astrophysics and Planetology, 00133 Roma, Italy

\begin{tabular}{|c|c|}
\hline . & $\mathbf{A C A V}^{+}$ \\
\hline 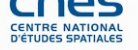 & * îledeFrance \\
\hline
\end{tabular}
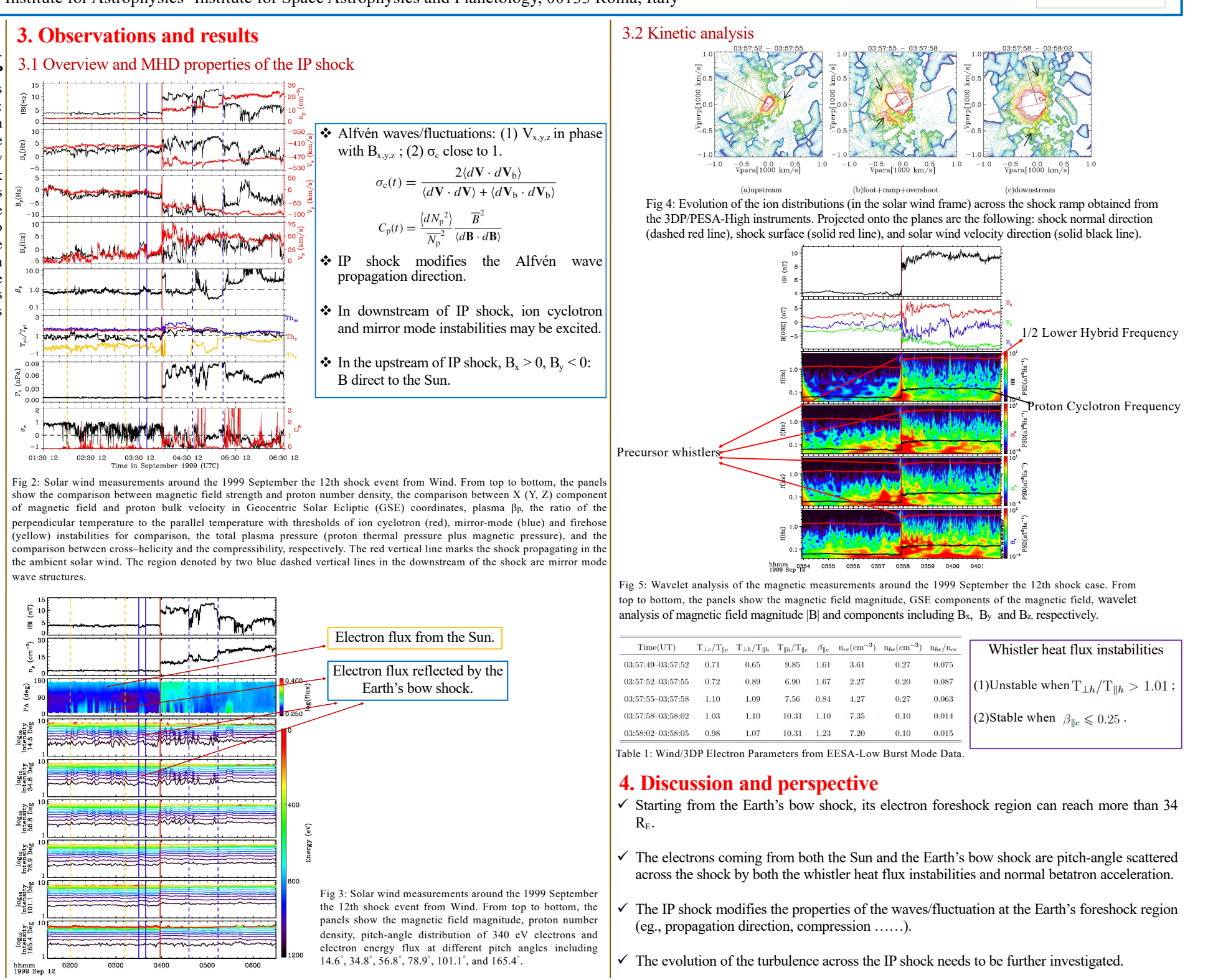

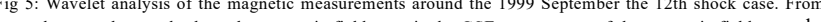
analysis of magnetic field magnitude $|\mathrm{B}|$ and components including $\mathrm{B} x \mathrm{x}$, $\mathrm{B}_{\mathrm{y}}$ and $\mathrm{B} z$, respectively.

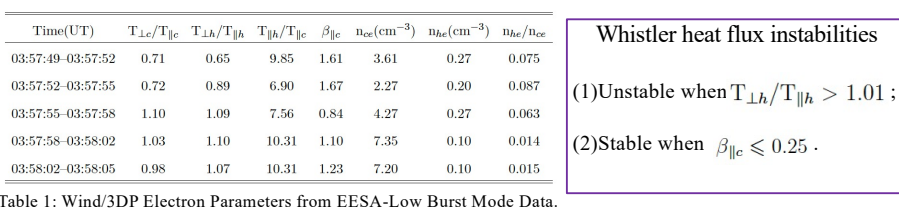
Table 1: Wind/3DP Electron Parameters from EESA-Low Burst Mode Data.

4. Discussion and perspective

$\checkmark$ Starting from the Earth's bow shock, its electron foreshock region can reach more than 34

The electrons coming from both the Sun and the Earth's bow shock are pitch-angle scattere across the shock by both the whistler heat flux instabilities and normal betatron acceleration.

$\checkmark$ The IP shock modifies the properties of the waves/fluctuation at the Earth's foreshock region (eg., propagation direction, compression .......).

$\checkmark$ The evolution of the turbulence across the IP shock needs to be further investigated. 